\title{
Ten years of improvements in health and health behaviour in the Spanish cohorts born between 1945 and 1969
}

\author{
Jeroen Spijker, Centre d'Estudis Demogràfics
}

Studies on health and health behaviour trends generally compare age-adjusted or age-specific rates. Conversely, a cohort perspective is rarely used, which impedes the possibility to observe, for a particular age, improvements or worsening in health conditions between cohorts. To cover this gap, in this issue of Perspectives Demogràfiques, health trends research is extended by analysing Spanish cohorts born between 1945 and 1969. The results show that despite the cohorts experiencing an economic crisis and becoming 10 years older, self-perceived health remained relatively similar with a tendency to improve between the years 2006-07 and 2014-17. Nevertheless, important differences according to educational level, employment status and sex persist. Health of higher educated employed men - and likewise women born in the 1960s - was unaffected by economic changes. On the other hand, the most disadvantaged are lower-educated men born between 1945 and 1959 as they reach retirement age, and lower-educated employed women, likely due to their double burden. Finally, employed women generally are in worse health than employed men, irrespective of educational level.

\section{THE 1945-69 SPANISH "TRANSITION TO DEMOCRACY" COHORTS}

The Spanish generation born between 1946 and 1969 experienced as adolescents and young adults, the transition from a dictatorship to a democracy entry into the European Union and other important economic and social changes. They were pioneers in embracing new family forms and had an important role in the legalization of contraception (1978), divorce (1981) and abortion (1985). One important factor behind these changes was educational expansion that had started in the 1960 s and particularly benefited women. Simultaneously, more women entered the labour force (Table 1), which facilitated a decline (without eliminating) in gender differences in the division of roles, as well as in lifestyle habits. Indeed, this generation is also unique regarding the role of individual attitudes about health, either by being the first en masse

to promote it through the adoption of healthier lifestyles or potentially harm it through drug use, smoking, traffic accidents or having multiple sexual partners. One feature that defined mortality trends of 20-39year-old Spaniards in the last two decades of last century was an increased risk of dying from life-stylerelated causes of death, particularly road accidents and HIV/AIDS and to a lesser extent suicides and drug addiction-related causes (Spijker and BlanesLlorens 2009).
TABLE 1. Socioeconomic and health characteristics according to cohort (ages 40-69)

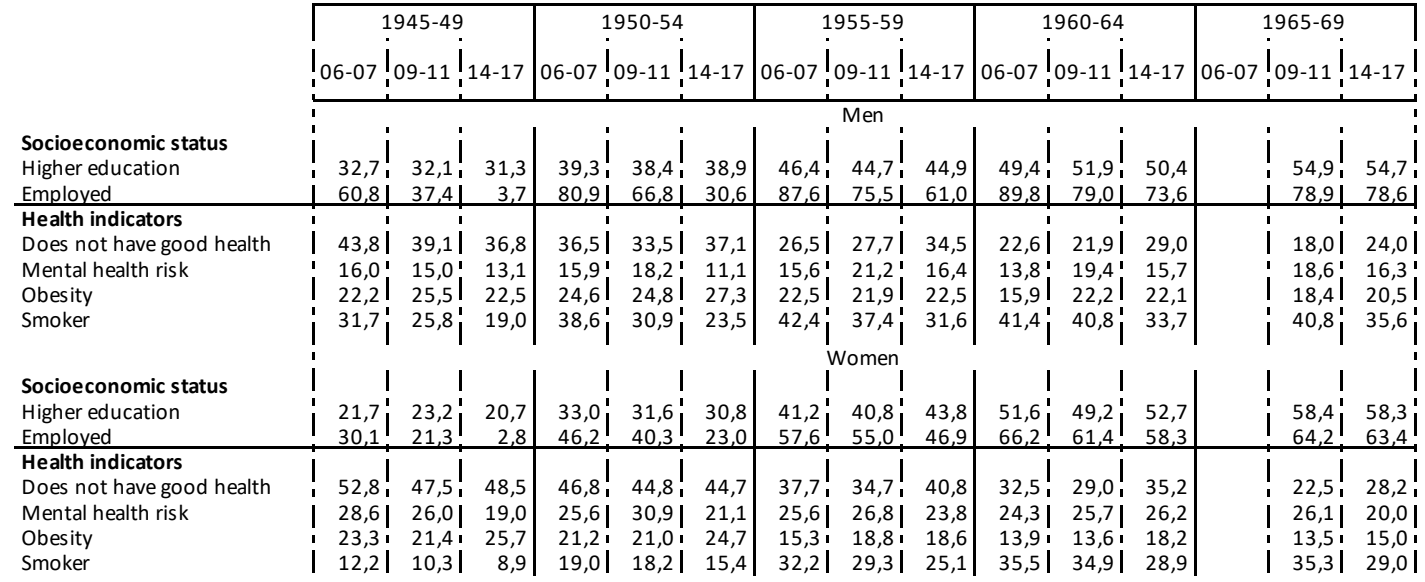

Source: Analyses based on data from the National and European Health Surveys (ENSE/EESE). The education categories were aggregated into "higher education" (upper secondary/vocational training/university) and "lower education" (illiterate/primary/ lower secondary). Employment is divided into "employed" and "not employed". To reduce the fluctuations in the results, the 2009 and 2011 waves and the 2014 and 2017 waves are aggregated. Self-perceived health - a well-known indicator of general physical, mental and social well-being-is based on the question: Would you say that your health status has been very good, good, regular, bad, very bad in the last 12 months? The last three responses have been grouped into the category "does not have good health". Mental health risk: Considered when the person obtains a score of $3+$ out of a maximum of 12 , based on 12 questions that value the mental health status of the respondent during the last 30 days. Obesity: Has a body mass index of 30 or more. Smoker: If the respondent smokes (daily or not daily). For this table, educational level and employment data come from the Spanish Labour Force Survey (Q2 for 2007, 2010 and 2016) as they are less consistent across cohorts in health surveys. 


\section{HEALTH TRENDS DURING MACRO- ECONOMIC FLUCTUATIONS}

The cohorts studied here experienced the economic crisis (200814) when aged between 40 and 69 years. This sparked renewed concern about how this would affect their health. Perhaps counterintuitively, however, previous studies have found greater improvements in health status and health-related behaviours such as increased hours of sleep and physical exercise due to more free time and less consumption of unhealthy food, tobacco or alcohol due to budget constraints (Karanikolos et al. 2013). More pronounced reductions have also been observed in total mortality and from major causes like cardiovascular diseases and diabetes during the years of economic stagnation than during the subsequent economic recovery period (Regidor et al. 2019). On the other hand, risks of poor mental health and suicide have been more reactive to adverse economic contexts (Bartoll et al. 2014; and Table 1). In addition, the less favoured social classes, such as the lower educated, unemployed and working class, always live fewer years and do so in worse health, although social differences did reduce during the last economic crisis (Spijker et al. 2018).

\section{TRENDS AND SOCIOECONOMIC DIFFER- ENCES IN SELF-PERCEIVED HEALTH FROM A COHORT PERSPECTIVE}

Even if overall health improved during the economic crisis for working aged adults, what about differences between cohorts? Further, what has happened since the economic crisis? As more recent data have become available, we therefore analyse for the 1945-69 cohort, trends in self-perceived health according to year of birth, age and sex. Given the known socioeconomic health differences, we also analyse trends by educational level and employment status and consider several other health indicators. Data are from two crosssectional and harmonised surveys: the Spanish National and European Health Surveys (waves 2006-07, 2009, 2011-12, 2014 and 2017). Variable definitions are described in Table 1.

As Figure 1 shows, at the same age, health improved between 2006-07 and 2009-11 (darker shades represent worse cohort and sex health than lighter shades). At the same age, self-perceived health improved slightly during the crisis years (2009-11) and remained the same during the following years (2014-17) (horizontal axis). As expected, with increasing age self-perceived health worsens during all periods (vertical axis). Conversely, through the cohort perspective (diagonal axis) utilised here it can be seen that the health of certain cohorts improve with age. The most obvious case is that of men born between 1945 and 1949, who experienced a slight improvement in self-perceived health between ages 55 and 70 , probably due to the "positive" health effects of the economic crisis and of retirement that was sufficient to counteract the normally "negative" effects of age. It is a result that coincides with previous studies and is explained by the adoption of better lifestyles, less work-related stress and more time for physical activities (Regidor et al. 2019).

Figure 2 shows how these trends have varied depending on the socioeconomic group. The data show a strong educational gradient: the higher the education level, the better the health. Also shows are differences depending on the employment status: those who work report better health than those who don't, especially among men. For cohorts, we observe stability or an improvement over time in the case of employed men and women: at the same age, younger cohorts have better health. The trend is more erratic among the non-employed. The proportion of higher-educated employed men without good health is very low, for instance, just 14\% among men born in 1965-69 and aged 40-44, but slowly increases with age and without important generational differences to about $20 \%$ for $55-59$

FIGURE 1. Proportion that does not have good self-perceived health according to age, period,
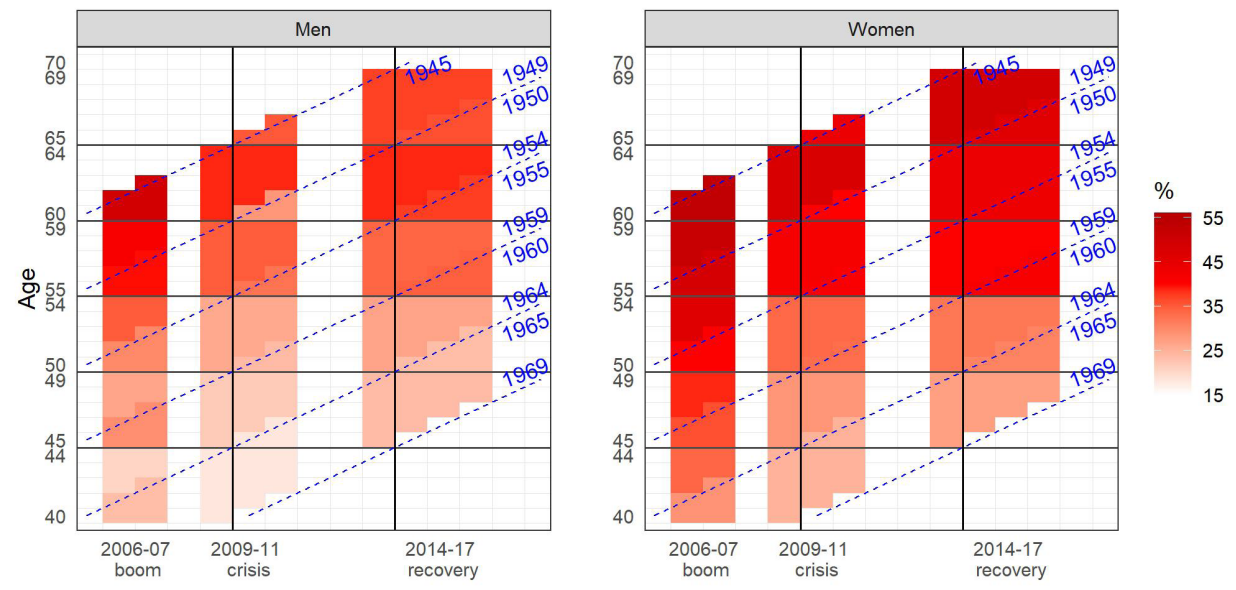

Source: ENSE/EESE. Interpretation: In this Lexis diagram possible age-, period and cohort effects in a variable of interest can be identified. Birth cohorts move along the $45^{\circ}$ lines, age is on the vertical axis and calendar time on the horizontal axis, corresponding to the years the surveys were taken (see also note Table 1). The colour denotes the value of the variable, here not having good self-perceived health, ranging from $15 \%$ (white) to $55 \%$ (dark red). 
FIGURE 2. Without good self-perceived health according to age and cohort
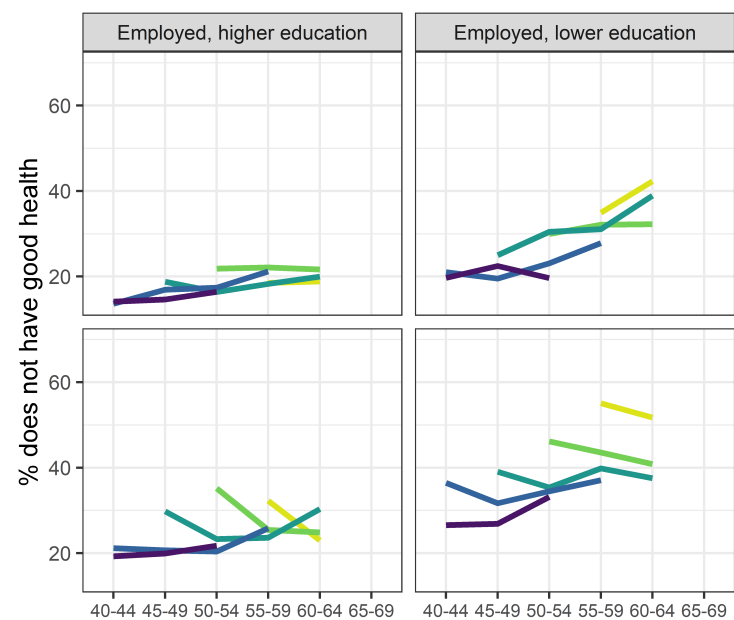

$40-44 \quad 45-4950-5455-5960-6465-69$

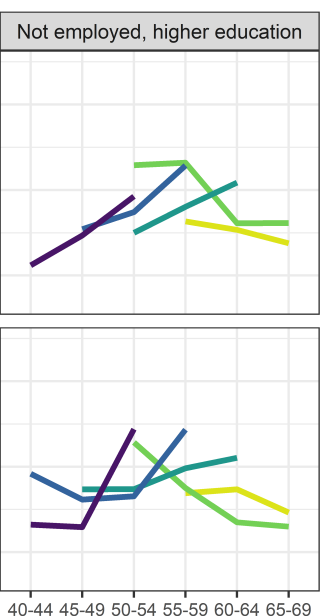

Cohort

- $1945-1949$

- $1950-1954$

- $1955-1959$

- $1960-1964$

- $1965-1969$

Source: $E N S E / E E S E$

year olds born earlier. Regarding similarly characterized women, the crisis greatly reduced the proportion without good health in the $1945-59$ cohorts to levels similar to the 1960 s cohorts. The decline in cohort differences is also observed among lower educated workers, especially in the case of women whose health improved between 2006-07 and 2009-11, but there are two noteworthy exceptions. Health outcomes worsened among lower educated employed men who approached retirement age and likewise women born in the 1960s. This is also observed among both sexes born between 1955 and 1969 who are higher educated and without work. In fact, they did not even experience health improvements during the crisis. Conversely, the health of the non-employed older cohorts improved markedly, irrespective of their education level (except for loweducated women).

Behavioural factors are obviously partly to blame for these socioeconomic differences. For instance, differences are quite perturbing for smoking (Fig 3) as rates among higher-educated male workers of all studied ages have declined in successive cohorts born after 1950, but this occurred later or not at all in the other socioeconomic categories. In the case of women, smoking was still rare among the 1945-49 generation, especially in the case of the lower educated, but began to converge with male rates in successive generations. However, over the last decade smoking rates have only declined among higher-educated workers born in the 1960s, who now have lower rates than the higher educated non-employed and the lower educated.

\section{HEALTH VERSUS GENDER, EMPLOYMENT INSECURITY AND (PRE-) RETIREMENT}

While self-perceived health was remarkably similar in 2014-17 to 2006-07 among all 1945-69 cohorts despite ageing about 10 years, there are many nuances when gender, certain cohorts, age groups and combinations of educational level and employment status are analysed. For instance, the proportion without good health, of higher educated employed men is very low but increases with age in each cohort. Yet, their health remains better than highereducated women who also work. While the younger women of this generation who experienced the transition to a democracy and free-market economy are more active in the labour market than older cohorts, the distribution of domestic work has barely changed and, as a result, neither their double burden. Moreover, women are more likely to have insecure work, lower salaries and be more exposed to emotional pressure than men, especially if they are also caregivers for an ailing relative. That said, gender health differences have almost disappeared among younger higher-skilled workers. But the health of lower-educated workers, especially women, also improved and educational health differences among workers even decreased. An explanation is that there has been a reduction in extra working hours and work-related stress and more time for

FIGURE 3. Smokers by cohort, sex, employment status and educational levelcohort

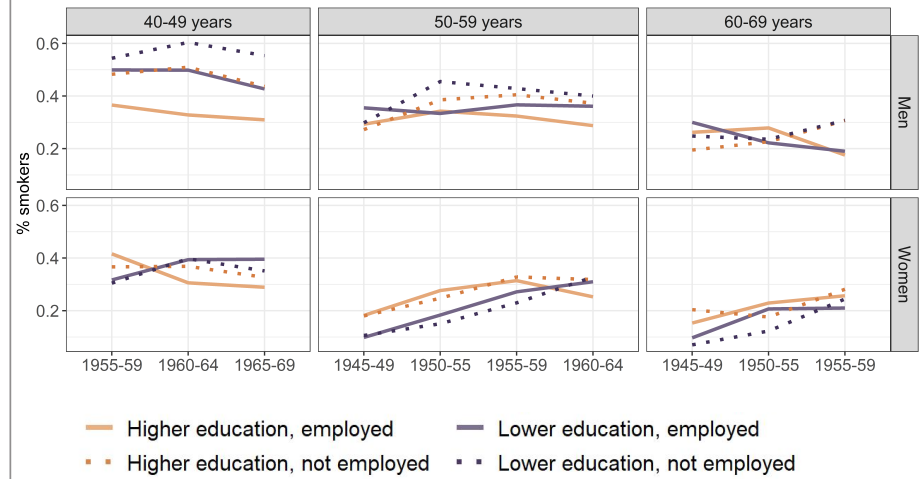

Source: ENSE/EESE 
physical activity since the economic recession. The high percentage of low-educated workers without good health when they approach retirement age (up to 55\% among 55-59 year-old women born in 1945-49) is, however, a concern. One would think that economic independence through salaries should improve the empowerment of women because a paid job is associated with higher levels of selfesteem, decision-making strategies and agency (OECD 2012). Still, for lower-educated older women employment is often a necessity and even more so during an economic crisis if she is the only income earner of a multi-person household.

In contrast, both the disappearance of work-related stress and the adoption of healthier lifestyles are factors that could explain the observed health improvements of non-employed men born in $1945-54$ once they pass the age of 60 . Another, not to be overlooked explanation, is because the composition of the non-employed becomes much more heterogeneous during an economic crisis. When there is almost full employment (as in 2006/o7; see Table 1) not working is much more likely to be due to health reasons than during an economic crisis when even high-educated (and often healthier) workers are laid off. That said, health among the lower educated without work is a major concern -about $60 \%$ of $55-59$ year old men (born late 1950s-late 1960s) with these characteristics were not in good health in 2014-17- suggesting that labour uncertainty and associated financial problems have a substantial effect on health. In fact, they had poorer self-perceived health than the older, and mainly retired, 1945-54 cohort. Among women, this tendency is less marked, partly because an important proportion are homemakers who are known to have a similar level of health as workers (Esteban-Gonzalo et al. 2018).

\section{Bibliography}

Bartoll, X.; Palència, L.; Malmusi, D.; Suhrcke, M Borrell, C. (2014). "The evolution of mental health in Spain during the economic crisis". European Journal Public Health, 24(3): 415-418.

Esteban-Gonzalo, S.; Aparicio M.; Estaban-Gonzalo, L. (2018). "Employment status, gender and health in Spanish women". Women \& health, 58: 744-758.

Karanikolos, M.; Mladovsky, P.; Cylus, J. et al. (2013). "Financial crisis, austerity, and health in Europe". Lancet, 381: 1323-1331.

OECD (2012). Women's economic empowerment. Paris: The OECD DAC Network on Gender Equality. Available from: http:// www.oecd.org/social/gender-development/47561694.pdf.

Regidor, E.; Ronda, E.; Tapia, Granados J. A. Viciana-Fernández, F. J; de la Fuente, L. Barrio, G. (2019). “Trends in disease mortality before and during the Great Recession in individuals employed in Spain in 2001". European Journal Public Health, 29 (5):954959.

Spijker, J.; Bayona, J.; Medina, A.; Menacho, T. (2018). Atles de salut de la població de 50 i més anys a Catalunya. Bellaterra: Centre d'Estudis Demogràfics. http://cedsaluticrisi. uab.cat/atlas/.

Spijker, J.; Blanes-Llorens, A. (2009). "Mortality in Catalonia in the context of the third, fourth and future phases of the epidemiological transition theory". Demographic Research 20: $129-168$

\section{Citation}

Jeroen Spijker (2019) "Ten years of improvements in health and health behaviour in the Spanish cohorts born between 1945 and 1969". Perspectives Demogràfiques, 17: 1-4.

\section{HOW WILL HEALTH AMONG THE YOUNGER TRANSITION TO DEMOCRACY COHORTS LOOK LIKE WHEN THEY REACH RETIREMENT AGE?}

The observed overall health improvements across successive cohorts, especially among women, will likely continue for three reasons: 1. Younger cohorts are better educated and education has a protective effect on health; 2. Younger female cohorts have higher labour force participation rates. Not only does employment have a protective effect on health, upon retirement more women will be receiving a contributory pension, making them less economic dependent on the state and/or their partners/family; and 3 . Improvements in health behaviours among younger cohorts. That said, one worrying tendency is the lack of convergence in socioeconomic differences in health behaviours among the younger cohorts, especially in obesity and smoking.

We therefore recommend public policies to continue to focus on promoting healthy lifestyles and strengthening social protection for vulnerable populations, but other policy areas are also likely to contribute to greater social equity in the health of current and future working-age cohorts, even if indirectly. Maintaining an affordable education system that curtails school dropout and fosters post-compulsory education is also imperative from a population health perspective because it reduces long-term health damaging behaviours and facilitates the effective use of health services. Additionally, education also increases labour force participation and, as we have seen, it is the higher-educated who work, who are by far in the best health. Ensuring secure and flexible employment is therefore just as important, in particular for the lower educated, for those who have few years left to retire and for women with a double workload.

\begin{tabular}{|c|c|}
\hline Editors & generació i territori" (2015 ACUP 00108) led \\
\hline $\begin{array}{l}\text { Andreu Domingo and Albert Esteve } \\
\text { (Centre d'Estudis Demogràfics) }\end{array}$ & $\begin{array}{l}\text { by J. Spijker. } \\
\text { URL }\end{array}$ \\
\hline $\begin{array}{l}\text { Please address correspondence to: } \\
\text { Jeroen Spijker } \\
\text { jspijker@ced.uab.es }\end{array}$ & $\begin{array}{l}\text { http://ced.uab.es/en/difusion/butlleti- } \\
\text { perspectives-demografiques }\end{array}$ \\
\hline $\begin{array}{l}\text { Graphics: Anna Turu } \\
\text { Layout: Xavier Ruiz Vilchez }\end{array}$ & $\begin{array}{l}\text { Centre d'Estudis Demogràfics. } \\
\text { Carrer de Ca n’Altayó, Edifici E2 } \\
\text { Universitat Autònoma de Barcelona } \\
\text { o8193 Bellaterra / Barcelona }\end{array}$ \\
\hline Acknowledgements: & $\begin{array}{l}\text { Spain } \\
\text { Telephone: +34 } 935813060\end{array}$ \\
\hline $\begin{array}{l}\text { Financial support for this research was pro- } \\
\text { vided by the Ministry of Science, Innovation } \\
\text { and Universities under the "Ramón y Cajal" } \\
\text { program (RYC-2013-14851) and carried out } \\
\text { within the framework of the RecerCaixa pro- } \\
\text { ject "Anàlisi demogràfica de les desigualtats }\end{array}$ & $\begin{array}{l}\text { Email: demog@ced.uab.cat } \\
\text { Web page: www.ced.uab.cat } \\
\begin{array}{c}\text { Universitat Autònoma } \\
\text { de Barcelona }\end{array}\end{array}$ \\
\hline
\end{tabular}

socioeconòmiques de la salut a Catalunya en el context de la darrera crisi econòmica: gènere, 